the increased number of those attaining present standards which will be forthcoming when the increased population passing through the schools reaches the university stage from 1962 onwards. He estimates that entrants in 1965 are likely on these assumptions to be 40-100 per cent above the present level, and that it is imperative to begin at once to erect the necessary buildings.

Lord Simon lays his main stress on technology. Pointing out that the number of degrees and diplomas in technology awarded by the universities in Great Britain has been decreasing since 1950 (from 3,593 to 3,359 ), he emphasizes that both the U.S.S.R. and the United States are already producing each year about twice as many graduates in science and technology per thousand of population as Great Britain, and that in the U.S.S.R. the output during the past five years has increased by more than 10 per cent a year. The Federal Institute of Technology at Zurich, he points out, has at present 2,700 full-time degree students, which is more than the three largest technological institutions in Britain put together, and the totals of 3,600 and 3,400 graduate engineers produced in Britain in 1950 and 1954, respectively, compare with 50,000 and 20,000, respectively, in the United States and 28,000 and 54,000 in the U.S.S.R. $\mathrm{He}$ urges that the rate of building for universities should be increased at once to provide reasonable accommodation for a 50 per cent increase in the number of students by 1965, and immediate and energetic action should also be taken to increase the output of graduates in technology by 10 per cent a year, with an ultimate output of at least ten thousand engineers a year. As a contribution to this end, he suggests the appointment of a small Royal Commission to report on the situation within six months.

\section{MATING SYSTEMS OF FUNGI}

$\mathrm{T}$ a paper under this title, J. H. Burnett (New Phytol., 55, 1, 50; 1956) has attempted to classify the principal kinds of mating systems, to devise an appropriate terminology for them, and to describe how they operate and are controlled. He points out that, so far, there is no adequate and agreed terminology for describing fungal mating systems.

The terminology now proposed includes the fol. lowing. Under the term 'heteromixis', he would include those instances, or imply the condition, where sexual reproduction only results from the fusion of genetically different nuclei normally derived from different thalli. Heteromixis includes: (1) 'dimixis', the condition where there are two, and only two, types of complementary nuclei which control mating, the nuclear types being determined by two allelomorphs at a single' locus; (2) 'diaphoromixis', the condition where several types of complementary nuclei occur which control mating, the nuclear types being determined by multiple allelomorphs at one or two loci, the bipolar and tetrapolar conditions, respectively; and (3) 'homoheteromixis', this being an essentially heteromictic condition where sexual reproduction results only from the fusion of genetically different nuclei derived normally from the same thallus; such forms are derived from dimictic or diaphoromictic forms, hence the derived terms, 'homo-dimictic' and 'homo. diaphoromictic'.
'Homomixis' is defined as the condition where sexual reproduction can result from the fusion of genetically similar nuclei, these being usually derived from the same thallus. 'Amixis' is defined as the condition where the essential events of sexual reproduction are lacking but where the pre-conjugation and post-meiotic events normally associated with sexual reproduction may occur. The author prefers this term to 'apomixis' since the condition described is one in haploid organisms. It is so defined as to cover a wider range of conditions than does apomixis as used for conditions in higher plants. The author describes how the principal mating systems operate, and concludes that the factors which control compatibility are pleiotropic in their effects. This sug. gests that mating-type factors are, in fact, groups of closely linked genes.

From a review of the evolution of mating systems, he concludes that it is not possible at present to give a general account of this phenomenon. It is, however, possible to make suggestions concerning the origin and evolutionary processes involved in some of the systems, and some hypotheses are developed. A general conclusion is that mating systems have arisen in a variety of ways and that, in the first instance, selection of potential mating-type factors may not have been for their effects upon compatibility.

\section{RESEARCHES IN THE ARCTIC OCEAN}

$T$ HE aretic, up to the North Pole, might be an open sea for part of each year if it were not for the piling up of pack ice into thick ridges by storms. Otherwise, ice formed during the intensely cold winter nights would be thawed completely by September. This speculation is advanced by Prof. G. E. MacGinitie, of the California Institute of Technology, in a technical report on arctic life just published by the Smithsonian Institution. Prof. MacGinitie was principal investigator at the Navy's Arctic Research Laboratory at Point Barrow, Alaska. It is highly improbable that the sea surface as a whole ever freezes during the winter to a depth of much over $6 \mathrm{ft}$. Thousands of lakes and ponds in the country behind the arctic coasts freeze to depths of more than $7 \mathrm{ft}$., yet this ice melts entirely during the summer.

During the storms of gale force that sweep over the arctic basin, the surface ice is piled up into windrows which may be several times $6 \mathrm{ft}$. thick. These drift together and constitute the great arctic pack. Summer melting is more than compensated for by the increased thickness of windrowed ice. Ice over offshore areas which has not been piled up by wind and wave disappears completely by September. The movement of the ice pack itself may have some influence on animal distribution. This pack constitutes about 70 per cent of the arctic ice. It is never stable. Previous investigations have shown that it may move as much as 1,000 miles in nine months. There is good evidence, Prof. MacGinitie says, for considering the pack as a great, moving field, the general direction of which is from north-east Siberia to the east of Greenland.

Prof. MacGinitie has also made some observations about Eskimo life. 